DOI: $10.15593 / 2224-9354 / 2019.1 .8$

УДК 005.35

\title{
А.В. Рушева
}

\section{СОЦИАЛЬНАЯ ОТВЕТСТВЕННОСТЬ БИЗНЕС-РЕШЕНИЙ}

Рассматривается важная сторона управленческой деятельности, связанная с социальными последствиями принимаемых решений, неоднозначно влияющими на общество. Разработка и контроль за последующим выполнением управленческих решений является ключевой функцией любого руководителя. Результат управленческого труда во многом зависит от личностных качеств лица, принимающего решение, от его профессиональной компетенции, системы ценностных ориентаций. Приведены примеры основных мотивов и инициатив, присущих субъектам бизнес-структур, осуществлять социально ориентированные практики. Несмотря на их наличие, принципы корпоративной социальной ответственности далеко не всегда учитываются при принятии управленческих решений, поскольку наряду с субъективными причинами есть разнообразные объективные ограничения.

Приведенные в статье примеры реализации социальных программ и мероприятий как зарубежными, так и отечественными предприятиями являются определенным подтверждением наличия мотивации и целей достижения социального благополучия. Но анализ практических достижений в области корпоративной социальной ответственности указывает на их довольно скромный, по сравнению с зарубежными компаниями, российский масштаб. Перечисление некоторых наиболее наглядных последствий деятельности социально безответственных отечественных организаций и описание созданных на основе глубокого переосмысления целей предпринимательской деятельности научных концепций и трудов актуализируют рассматриваемую проблему, заставляют задуматься о необходимости применения уже имеющегося богатого опыта социальной благотворительности, вложения в человеческий капитал, обеспечения устойчивого функционирования предприятия на рынке и получения прочих положительных социально-экономических результатов.

В качестве основных выводов проведенного анализа проблемы выступают рекомендации по применению системного подхода к разработке и принятию управленческих решений, обеспечивающего более полный взгляд на ситуацию, позволяющего учесть не только экономические и политические интересы руководства, но и множество социальных последствий предпринимаемых действий. Также, по мнению автора, важно закрепить в соответствующих организационных документах принципы корпоративной социальной ответственности, продумать механизм их реализации.

Ключевые слова: социальная ответственность, управленческое решение, руководитель, организационное окружение, корпоративное управление, государство, достижение целей, мотивация, социальное благополучие.

Сравнивая решения, которые мы принимаем для себя (т.е. исходя из собственных суждений и личных целей), и действия, совершаемые лицом, занимающим официальную управленческую должность, можно увидеть немало различий. Большинство особенностей управленческих решений связано с высоким уровнем ответственности менеджера, с требованиями к его профессионализму, масштабом влияния его выбора и, безусловно, целями, которые он ставит.

(C) Рушева А.В., 2019

Рушева Анна Витальевна - канд. социол. наук, доцент кафедры общей социологии и социальной работы ФГАОУ ВО «Национальный исследовательский Нижегородский государственный университет им. Н.И. Лобачевского» (ННГУ), e-mail: avr0201@yandex.ru. 
Управленческое решение - это выбор, который совершает руководитель, реализуя данные ему полномочия. Следует заметить, что в условиях демократизации социально-трудовых отношений и иных изменений, продиктованных мировыми тенденциями, в российской практике управления все чаще стала практиковаться коллегиальная форма разработки и принятия решений. Несмотря на некоторое «отступление» от классических принципов единоначалия и единораспорядительства, подобный подход все же предполагает, что управленческое решение принимается в четко определенных формальных рамках, с учетом нормативно-правовых норм и на основании имеющейся компетенции менеджеров. Нельзя сказать, что данный фактор однозначен: предполагаемый порядок действий и соблюдение установленных правил и процедур очень сильно ограничивают возможности выбора, необходимого для принятия качественного решения.

Еще одной отличительной чертой решения руководителя является обязательный учет и анализ организационного окружения при его разработке. Формулируя цель и составляя план действий для ее достижения, современный менеджер изучает влияние факторов внутренней и внешней среды, минимизируя/исключая тем самым различные негативные последствия для организации.

Очевидно, что за большей частью вышеперечисленных особенностей управленческого решения кроется личность менеджера. Каждая ее характеристика является важной и весомой, поскольку в той или иной степени она проявляется в принимаемых руководителем решениях и впоследствии - в результатах. Приведем примеры таких черт личности управленца: психологические (темперамент, воля, мышление, потребности, мотивы, установки и пр.); профессиональные (знания, умения, опыт, навыки и т.д.); социальные (лидерские качества, активность, мировоззрение, система ценностей).

Несмотря на активное развитие цифровых технологий, расширение средств связи и иных достижений научно-технического прогресса, среда, в которой руководитель принимает решение, в настоящее время наделена достаточно высоким уровнем неопределенности и нестабильна. Данное обстоятельство затрудняет определение четких критериев, позволяющих оптимизировать выбор. В этой связи актуализируются личностные качества управленца, накопленный опыт, интеллектуальные и творческие способности сотрудников, степень их мотивированности и пр.

Определенное воздействие на поведение менеджеров при принятии решений оказывают и такие объективные факторы, как сфера деятельности, форма собственности предприятия, характеристики непосредственного социального окружения, а также масштаб управления. Так, например, заметна существенная разница между условиями разработки решений госслужащих и руководителей коммерческих структур: конкурентные силы, присущие 
бизнес-среде оказывают более сильное влияние на успех и возможности частных предприятий, нежели государственных, требуют большей гибкости, оперативности действий, инновационных взглядов.

По мере развития общества постепенно меняются и порой повышаются требования потребителя к конечному продукту. В настоящее время одним из самых важных и ожидаемых эффектов от деятельности предприятия наряду с экономическими показателями является социальное благополучие. Ориентация менеджмента при принятии решений не только на сиюминутную выгоду и быстрый результат, но и на применение системного подхода к управлению обеспечивает спрос на свою продукцию и устойчивость компании как в настоящем, так и в будущем. Данные принципы ведения бизнеса уже неоднократно доказали свою полезность. Для большинства международных компаний уровень социальной ответственности компании является важным критерием при принятии управленческих решений, практически отождествляется с еe репутацией, оказывает на нее прямое влияние и обеспечивается кропотливой работой над множеством социально значимых проектов. По данным Глобального рейтинга самых социально ответственных компаний (Global CSR RepTrak) 2016 года, в ТОП-10 входят всем известные корпорации, такие как Google Microsoft, TheWaltDisneyCompany, BMW, LEGO и др. Аналитики Reputation Capital Group утверждают, что высокая оценка их репутации на 40 \% зависит от ее восприятия как социально ответственной [1], что на деле означает не только широкое информирование о социально направленных мероприятиях, но и их успешную реализацию, ощутимые потребителями результаты.

Одно из первых определений социальной ответственности дал американский ученый Г. Боуэн (Howard Bowen), опубликовавший в 1953 году свою работу «Социальная ответственность бизнесмена». В ней автор представляет ключевые направления изучения социальной ответственности бизнеса, подчеркивая, что она состоит «в осуществлении такой политики, принятия таких решений, либо следовании такой линии поведения, которые были бы желательны для целей и ценностей общества» [2].

Большую распространенность приобрела модель А. Керролла, согласно которой корпоративная социальная ответственность является многоуровневой, представляет собой пирамиду, включающую экономическую, правовую, этическую и филантропическую ответственность. По мнению автора, «исповедующая КСО фирма должна стремиться получать прибыль, быть этичной, а также быть хорошим корпоративным гражданином» [3].

В современном мире корпоративными структурами реализуются, как правило, две уже сформировавшиеся и устоявшиеся модели корпоративной социальной ответственности: американская и континентально-европейская. Главным отличием американской модели является минимальная роль государства в деятельности частного бизнеса, который активно поддерживает 
традиции добровольного финансирования разнообразных социальных проектов (образовательные программы, пенсионные и страховые системы и др.). Такие социально ответственные решения поощряются государством определенными налоговыми льготами и поощрениями, закрепленными в законодательстве.

Особенностью европейской модели КСО является ее государственное регулирование. Это проявляется, прежде всего, в закрепленном законодательно институте обязательного добровольного страхования и охраны здоровья работников, пенсионного страхования. Большинство острых социальных проблем, в том числе и в сфере труда и трудовых отношений, решаются на уровне государства через механизмы государственной социальной политики [4].

Учитывая объективные экономические условия функционирования бизнеса и социокультурную специфику стран, выделяют также канадскую, китайскую, японскую, исламскую, латиноамериканскую модель КСО.

Российский же подход к реализации принципов социальной ответственности пока находится на стадии формирования. Между тем яркие проявления гуманизма, доброты, альтруизма были присущи российским деятелям и предпринимателям во все времена. Вспомним известные всем имена великих российских деятелей и меценатов: С.Г. Строганова, братьев Третьяковых, С.И. Мамонтова, С.Т. Морозова, династию Бахрушиных, К.Т. Солдатенкова и многих других, благодаря которым произошли существенные и исторически значимые изменения в образовании, искусстве, науке, медицине.

Несмотря на богатый отечественный опыт выполнения коммерческими структурами экономических и социальных обязательств перед обществом, в настоящее время достаточно остро стоит вопрос об институционализации российской модели КСО. Современная практика корпоративного управления свидетельствует о наличии множества разнообразных мотивов, побуждающих компании осуществлять социально ориентированную деятельность. Так, согласно результатам масштабного исследования, проведенного ЗАО «КПМГ» и Фондом «Единое общество» [5], ключевым мотивом осуществления крупными бизнес-структурами социальной деятельности выступают личные ценности руководителей (35 \% российских и 32 \% иностранных). Другими факторами, нацеливающими на соблюдение социальной ответственности, являются традиции компании (27 и 16 \% соответственно), корпоративные требования (8 и $10 \%$ соответственно) и повышение значимости бренда ( 8 и $13 \%$ соответственно). Любопытно, что мотивы «религиозные воззрения» и «экономическая выгода» не были упомянуты ни одним респондентом крупного бизнеса, в то время как для отечественных средних и малых коммерческих предприятий первый фактор является достаточно важным (15 и $16 \%$ соответственно). 
Наиболее весомыми факторами при принятии решений об осуществлении социальной деятельности в большинстве крупных российских и иностранных компаний, по данным опроса опять же стали моральные и этические воззрения; на них же указали и более 20 \% представителей российского среднего бизнеса. Для всех, без исключения, опрошенных организаций, большое значение при формировании ответственного бизнеса имеет национальная культура и традиции (порядка 18 \% всех респондентов). Определенную роль в принятии решений о ведении социальной деятельности играют и политические, и административные стимулы (14\% крупных российских и $15 \%$ иностранных компаний) [5].

Нацеленность на обеспечение конкурентоспособности в современных социально-экономических условиях, характеризующихся активным развитием на территории России зарубежного сектора (в лице инвесторов, поставщиков, конкурентов, потребителей и пр.), не должна служить оправданием непродуманных спонтанных и непрофессиональных решений, нарушающих права и свободы граждан. Также и сосредоточение интересов субъектов корпоративного управления лишь на достижении коммерческой цели извлечения прибыли (зачастую всеми возможными способами) имеет множество отрицательных последствий, распространяющихся как на собственных работников, так и на общество в целом. Подобное поведение лиц, принимающих решения, свидетельствует об ограниченности и/или преобладании личных интересов, о некомпетентности и отсутствии должных морально-нравственных взглядов.

В. Зомбарт, немецкий экономист и социолог, в своей известной книге «Буржуа» отмечал: «...Но все, кто служил капитализму: крупный землевладелец и крупный заморский купец, банкир и спекулянт, мануфактурист и шерстоторговец - все они все-таки не переставали соразмерять свою коммерческую деятельность с требованиями здоровой человечности: для всех их дело осталось только средством достижения цели жизни; для всех их направление и меру их деятельности определяют их собственные жизненные интересы и интересы других людей, для которых и вместе с которыми они действуют... Богатство ценится, нажить его - желаемая цель жизни, но оно не должно быть самоцелью; оно должно только служить тому, чтобы создавать или сохранять жизненные ценности» [6].

Сегодня реальность такова, что про «здоровую человечность» многие управляющие забывают. О низком качестве и непродуманности управленческих решений, принимаемых менеджерами самых разных предприятий, фирм и корпораций, и степени их социальной ориентированности можно судить по многочисленным примерам, о которых, например, нам ежедневно сообщают СМИ. Вспомним недавние ситуации, связанные с «неожиданным» банкротством авиакомпаний, которые не в состоянии выполнить взятые на себя обязательства перед пассажирами и осуществить их перевозку, или туроперато- 
ра, «вдруг» оказавшегося нежизнеспособным, хотя о его деятельности известно не только клиентам, но и всем надзорным государственным органам. Можно усомниться также и в честности руководства многих строительных компаний, собравших с «будущих» добросовестных «собственников» жилья деньги, вводящих их в заблуждение о сроках выполнении строительных работ и быстро покидающих страну, умело уходя от ответственности.

Список социально безответственных организаций пополнен и некоторыми медицинскими клиниками, оказывающими некачественные услуги и достаточно легко нарушающие главные постулаты своей деятельности. Практически каждый день каждому из нас приходится сталкиваться с проблемой плохих дорог или вовсе их отсутствия, что также «лежит на совести» и подрядчиков - строительно-дорожных компаний, и тех, кто дает им право «выиграть тендер». Не меньше претензий высказывается и в адрес производителей продуктов питания, которые не осуществляют должный контроль за их качеством, нанося тем самым серьезный вред здоровью потребителя.

Заглянув «внутрь» предприятия, все чаще и чаще мы видим всевозможные ущемления прав работников, нарушения положений трудового законодательства. За такими фактами, как задержка или невыплата заработной платы, «серые» схемы ее начисления, отсутствие системы поощрения, в том числе и за сверхурочную работу, вредные для здоровья условия деятельности, несоблюдение техники безопасности, опять же «стоят» люди - собственники организаций, менеджеры, наделенные правом принимать решения и оказывать воздействие. Подобные ситуации принимаются трудовым населением крайне негативно. Но даже имеющиеся в судебной практике попытки восстановить справедливость и призвать к ответу недобросовестного работодателя или производителя, как правило, заканчиваются плачевно для инициативного работника и свидетельствуют о его чрезвычайно малых шансах противостоять «облеченным во власть» (при отсутствии социальной ответственности).

В свою очередь, очевидные положительные последствия от заботы о людях как о «живых машинах» были отмечены еще на заре становления научного управления (Р. Оуэн [7], Т. Шульц [8], А. Смит и др.). Очевидный экономический эффект в условиях рынка от инвестиций в человеческие ресурсы/капитал подтверждаются и более современными теориями (Г. Беккер [9], Т. Стюарт [10], К.Р. Макконнелл, С.Л. Брю [11] и др.).

Вся история предпринимательства - его напряженный диалог с обществом, постоянное решение вопроса о соотношении экономической и внеэкономических сторон жизни. При этом либо экономика существует для удовлетворения многообразных внеэкономических потребностей общества, а предприниматель стремится показать, что разделяет его интересы, несет те же тяготы - такая позиция формирует этос служения; либо утверждается приоритет экономических и формально-правовых сторон жизни над всеми ос- 
тальными, и тогда прибыль становится самоцелью для предпринимателя, а он противопоставляет себя обществу, методично извлекая выгоду из всего, в том числе из человеческих отношений, морали, культуры, религии, или просто игнорируя их [12].

Вложения в человеческий капитал являются не только расходами на воспроизводство рабочей силы, а долгосрочными инвестициями, которые расширяют способности, укрепляют здоровье человека, способствуют росту производительности труда и увеличению доходов работников [13].

Формирование концепции корпоративной социальной ответственности (КСО) происходило на протяжении долгого периода времени. В научной литературе выделяется как минимум 5 этапов развития КСО (с 1970-х годов), когда были созданы: теория корпоративного эгоизма, теория корпоративного альтруизма, одна из самых сильных «центристских» доктрин - теория «разумного эгоизма», интегрированный подход к социальной ответственности (1990-е годы), а также более поздние концепции, устоявшиеся сегодня, например, теория «корпоративной совести», «корпоративное гражданство», «социально ответственное инвестирование», концепция заинтересованных сторон и пр.

Согласно определению Международной организации по стандартизации, социальная ответственность - это «ответственность организации за воздействие ее решений и деятельности на общество и окружающую среду через прозрачное и этичное поведение, которое содействует устойчивому развитию, включая здоровье и благосостояние общества; учитывает ожидания заинтересованных сторон; соответствует применяемому законодательству и согласуется с международными нормами поведения; введено во всей организации; интегрировано в деятельность всей организации и применяется в ее взаимоотношениях» [14].

Принципы КСО определяют смысл и содержание организации, формируются, как правило, исходя из ожиданий общества и конкретных заинтересованных сторон и охватывают все направления ее деятельности. Такая интерпретация КСО представляет ее как современный подход к стратегическому управлению, предполагающий системный взгляд на принятие решений и ведение бизнеса.

В российских условиях социальная ответственность бизнеса чаще всего реализуется как реакция на необходимость решения острых социальных проблем. Сложившаяся в постперестроечное время ситуация способствовала углублению разрыва между богатыми и бедными, слабости гражданского общества, разочарованию в способности государства выполнять свои функции [15]. Благоприятными факторами становления социальной ответственности бизнеса в России являются: исторические традиции социального служения предпринимательства, процессы глобализации, приводящие к распространению социальной ответственности и среди российских компаний, наличие 
мощных корпоративных структур, располагающих возможностями социальных инвестиций, повышение репутации компании и обеспечение доверия потребителя, конструктивное взаимодействие с органами государственной власти в целях обеспечения поддержки, административными и информационными ресурсами.

О том, что определенная доля отечественных предприятий осуществляет свою деятельность с учетом социокультурного фактора, свидетельствуют, например, данные отчетов компаний, вошедшие в Доклады о социальных инвестициях в России (2004, 2008, 2014 годов). Указанные документы содержат анализ «лучших практик» КСО ведущих российских компаний и тенденции их развития.

Так, важность ведения деятельности по решению социальных задач подтверждают сведения о создании в корпорациях специальных подразделений или наделении дополнительными функциями уже действующие службы: контроль за решением вопросов КСО ведут департаменты по управлению персоналом - в 59 \% компаниях-респондентов и службы по связям с общественностью - на 39 \% предприятиях.

Основной закономерностью, которая прослеживается в ответах всех компаний-респондентов, является значительное превалирование двух направлений - развития персонала $(43,5$ \%) и поддержки местного сообщества (20,3 \%), причем различия между группами отраслей в этой области существенно нивелируются (от 42,1 \% в сфере услуг до 45,9 \% в сырьевом секторе). При расчете качественного индекса были использованы три группы критериев: институциональное оформление социальной политики компании, развитость системы учета социальных мероприятий и степень комплексности реализуемых социальных инвестиций.

Вышеприведенные данные, безусловно, свидетельствуют о наличии заинтересованности руководства предприятий как во «внутреннем», так и во «внешнем» социальном благополучии. Тем не менее, обобщая результаты проведенного исследования, заключим, что количественный и качественный индексы социальных инвестиций российского бизнеса за исследуемый период не продемонстрировали положительной динамики. Формирование устойчивой группы компаний-лидеров, соответствующих лучшим мировым образцам корпоративной социальной деятельности, происходит на фоне общего замедления процесса интеграции принципов КСО в корпоративную стратегию [16].

Одним из главных факторов сдерживания развития социальной ответственности российского бизнеса является слабовыраженная социальная ответственность ключевого социального института - государства. Трудно заставить или мотивировать предпринимателей продумывать социальные последствия принимаемых решений, если государство ведет себя совсем иначе; они не видят причинно-следственную связь между успехом в бизнесе и социально 
ответственным поведением. В научном управлении есть закон «эталонного поведения», согласно которому подчиненные ориентируются на действия своего руководителя/лидера. Если чиновники думают только о своей выгоде, совершают коррупционные сделки, не выполняют положенные по закону социальные функции, используют связи с криминалом, заботятся о личных интересах в ущерб обществу, то эти и иные явно заметные в образе жизни и деятельности порядки и практики властных групп провоцируют аналогичное поведение на микроуровне, негативно отражаются на принимаемых управленческих решениях субъектами бизнеса [17].

Очевидно, что проблема формирования социально ответственного поведения довольно сложная, многоуровневая, а потому требует больших усилий и продолжительного периода времени. Вектор социальной направленности «желаемых» качеств членов социальной общности будет во многом определяться социальными целями, задачами, идеалами субъектов, участвующих в формировании человеческого потенциала. Если принимаемые ими решения и последующие действия соответствуют интересам национальной общности, то общество получит его «прирост». Если эти же группы замкнуты на себе, а государство служит этим узким целям, то человеческий потенциал будет поглощаться верхушкой социальной структуры [18].

Из вышеизложенного следует вывод о необходимости увеличения (стимулирования) вклада субъектов бизнеса (причем любого масштаба!) в улучшение качественных характеристик населения, рассматривать его надо как фактор экономического роста и стратегического развития, в том числе и самого предприятия. Мотивами подготовки и осуществления социально значимых мероприятий, постановки социально ориентированных целей и принятия социально ответственных управленческих решений могут быть:

1) повышение производительности труда работников;

2) решение проблемы текучести кадров;

3) создание более привлекательных условий для найма и работы высококвалифицированного персонала;

4) дополнительное информирование в СМИ о выпускаемой продукции и деятельности компании;

5) создание положительного имиджа организации и ее брендов;

6) льготы налогового законодательства;

7) обеспечение стабильного положения предприятия на рынке и перспектив его дальнейшего развития в регионе;

8) возможность участия в инвестиционных программах, реализуемых на федеральном и/или региональном уровне и пр.

Более глобальным и перспективным направлением в изменении сложившейся ситуации неразвитости в культуре управления принципа социальной ответственности является постепенная, системная и планомерная транс- 
формация сферы социокультурных ценностей и поведенческих норм. Нужно отметить, что некоторые изменения в определенных формах уже происходят. Так, например, значимость реализации принципов КСО отражается в Федеральном государственном образовательном стандарте высшего профессионального образования для бакалавров, обучающихся по направлению «Менеджмент». Данный документ был разработан при активном участии ВШМ СПбГУ и принят еще в 2010 году. Согласно этому стандарту дисциплина «Корпоративная социальная ответственность» обязательна для изучения и направлена на развитие в выпускниках - будущих менеджерах необходимых профессиональных компетенций, обучение ключевым принципам управления корпоративной социальной деятельностью, распространение наиболее эффективных мировых и отечественных практик.

Исследование уровня развития и распространения принципов корпоративной социальной деятельности продолжается; в нашей стране проводятся мероприятия по изучению и измерению уровня социальной ответственности принимаемых субъектами корпоративного управления решений. В 2008 году был запущен проект «People Investor» [19], целью которого было создание сообщества бизнесменов, которые в качестве первостепенного фактора развития компании рассматривают ресурсы, не имеющие материальной сущности, но приносящие организации экономическую выгоду (например, персонал, профессиональные знания, партнерские отношения и социальные связи, репутация и пр.). Основное предназначение проекта заключается в содействии выявлению и распространению наилучших примеров и инновационных практик реализации социально значимых целей бизнесструктурами и социально ответственного поведения. В настоящее время в рамках данного проекта проводится XI конкурс корпоративных проектов и форум с одноименным названием. Главная его идея состоит в поддержке и стимулировании компаний, уделяющих особое внимание социальным инвестициям и решающих важные социально-экономические задачи в области устойчивого развития.

Как было указано выше, Ассоциация менеджеров России с 2004 года осуществляет подготовку национальных Докладов о социальных инвестициях бизнес-структур. Формируемый на основе исследований ведущих российских компаний Доклад 2018 года представляет собой результаты работы Ассоциации в сфере развития и распространения в России ключевых принципов концепции КСО [20]. Эти и ранее изданные материалы актуальны и содержательны, доступны всем заинтересованным лицам, способствуют формированию и развитию отечественной модели корпоративного управления; их анализ и применение положительного опыта передовых компаний на практике позволяют повышать качество деятельности и уровень их социальной ориентированности. 
На основании вышеизложенного сделаем некоторые вblводы:

1. Управленческие решения являются ключевым элементом процесса управления любой организацией, результатом управленческого труда. Исходя из положений общей теории принятия решений управленческое решение это всегда выбор, который совершает руководитель (или группа уполномоченных лиц), на основе своих знаний и опыта, в результате анализа информации и совершает его во благо организации и ее окружения.

2. Процесс управления предприятием необходимо выстраивать на основе системного подхода, неотъемлемым элементом которого является планирование и ведение корпоративной социальной деятельности. Признанная во второй половине XX века системная методология в менеджменте, в настоящее время приобрела особую актуальность, поскольку на фоне мощного и постоянного развития научно-технического прогресса, внедрения в практику управления знаний социально-психологических наук, организационная система существенно усложнилась. Современное предприятие требует иного восприятия, применения таких подходов, методов и форм воздействия, которые бы представляли его в виде системы, как совокупности взаимосвязанных, взаимодействующих и взаимозависимых элементов. Разработка управленческих решений с этой позиции дает возможность учесть ее основные свойства (целостность, синергия (эмерджентность), устойчивость), а также выстроить успешную стратегию развития.

3. В качестве рекомендаций для эффективного менеджмента, направленного на перспективу и имеющего социальную ориентацию, можно предложить: детально прописанные (в целях реалистичности) принципы КСО, которые логично поместить в этическом кодексе компании; тщательно продуманный механизм взаимодействия с заинтересованными сторонами (в том числе и с персоналом организации), выстроенный на постоянной основе и имеющий обратную связь; разработку форм нефинансовой отчетности, соответствующих международным стандартам и наглядно отражающих достигнутые социально ориентированные цели; поддержку государственными органами власти социально направленной стратегии и конкретных мероприятий, формирование, в первую очередь у субъектов управления, понимания значимости социальных задач для стратегического развития бизнеса.

\section{Список литературы}

1. Кто самый ответственный [Электронный ресурс] // Устойчивый бизнес. - 2017. - 11 мая. - URL: http://csrjournal.com/24649-kto-v-mire-samyjotvetstvennyj.html (дата обращения: 02.12.2017).

2. Bowen H.R. Social Responsibilities of the Businessman. - New York: Harper and Row, 1953. - $276 \mathrm{p}$. 
3. Carroll A. B. The Pyramid of Corporate Social Responsibility: Toward the Moral Management of Organizational Stakeholders // Business Horizons. - 1991. Vol. 34, no. 4. - P. 43.

4. Нехода Е.В., Раковская В.С. Реализация корпоративной социальной ответственности в России: проблемы, возможности, перспективы // Современные проблемы науки и образования: электрон. науч. журн. - 2014. № 5. - URL: https://science-education.ru/ru/article/view?id=14707 (дата обращения: 10.09.2018).

5. Аналитический обзор по результатам исследования «Ценностные основы социальной деятельности российского предпринимательства» / Группа компаний «НОВАРД». - М., 2015. - С. 25-27.

6. Зомбарт В. Буржуа. - М.: Наука, 1994. - 448 с.

7. Блауг М. Оуэн, Роберт //100 великих экономистов до Кейнса = Great Economists before Keynes: An introduction to the lives \& works of one hundred great economists of the past. - СПб.: Экономикус, 2008. - $352 \mathrm{c}$.

8. Schultz T.W. Investing in People: The Economics of Population Quality. Berkeley: University of California Press, 1981. - 173 p.

9. Беккер Г.С. Человеческое поведение: экономический подход. Избранные труды по экономической теории. - М.: Изд. дом ГУ ВШЭ, 2003. - 672 с.

10. Стюарт Т.А. Интеллектуальный капитал: новый источник богатства организаций / пер. с англ. В. А. Ноздриной. - М.: Поколение, 2007. - 366 с.

11. Макконелл К.Р., Брю С.Л. Экономикс. - М.: ИНФРА-М, 2003. - 983 с.

12. Зарубина Н.Н. Этика служения и этика ответственности в культуре русского предпринимательства [Электронный ресурс] // Общественные науки и современность. - 2004. - № 1. - С. 96. - URL: http://ecsocman.hse.ru/data/ 2011/01/11/1214867120/Zarubina.pdf (дата обращения: 01.10.2018).

13. Новикова В.Ф. Инвестиции в человеческий капитал в России как фактор социально-экономического развития страны [Электронный ресурс] // Современные технологии управления. - 2014. - № 2 (38). - URL: http://sovman.ru/article/3805/ (дата обращения: 22.11.2017).

14. ГОСТ Р ИСО 26000-2012. Руководство по социальной ответственности ISO 26000:2010 [Электронный ресурс]. - URL: http://allgosts.ru/03/100/ gost_r_iso_26000-2012 (дата обращения: 27.09.2017).

15. Шихвердиев А.П., Серяков А.В. Социальная ответственность бизнеса как элемент эффективного корпоративного управления [Электронный ресурс] // Вестник Научно-исследовательского центра корпоративного права, управления и венчурного инвестирования Сыктывкарского государственного университета. - 2008. - № 1. - URL: http://koet.syktsu.ru/vestnik/2008/20081/8/8.htm (дата обращения: 07.09.2018).

16. Доклад о социальных инвестициях в России - 2014: к созданию ценности для бизнеса и общества [Электронный ресурс]. - URL: http:// 
www.amr.ru/upload/iblock/da4/da487a01f2bed5773ea4e9f8523567fc.pdf (дата обращения: 04.09.2018).

17. Нифаева О.В. Активизация социальной ответственности российского предпринимательства // Менеджмент в России и за рубежом. - 2012. № 5. - C. 42-44.

18. Аргунова В.Н. Человеческий потенциал как цель и средство общественного развития // Трансформация человеческого потенциала в контексте столетия: в 2 т. / под ред. проф. З.Х. Саралиевой. - Н. Новгород: Изд-во НИСОЦ, 2017. - Т. 1. - С. 97.

19. XI форум корпоративных проектов «Реople Investor» [Электронный pecypc]. - URL: http://peopleinvestor.ru/ (дата обращения: 04.09.2018).

20. Доклад о социальных инвестициях в России в 2018 году [Электронный ресурс] / Ассоциация менеджеров России. - URL: http:/www.amr.ru/ projects/1111/ (дата обращения: 04.09.2018).

\section{References}

1. Kto samyi otvetstvennyi [Who is the most responsible]. Available at: http://csrjournal.com/24649-kto-v-mire-samyj-otvetstvennyj.html (accessed 2 December 2017).

2. Bowen H.R. Social responsibilities of the businessman. New York, Harper and Row, 1953, 276 p.

3. Carroll A. B. The Pyramid of corporate social responsibility: Toward the moral management of organizational stakeholders. Business Horizons, 1991, vol. 34, no. 4, p. 43 .

4. Nekhoda E.V., Rakovskaia V.S. Realizatsiia korporativnoi sotsial'noi otvetstvennosti v Rossii: problemy, vozmozhnosti, perspektivy [The implementation of corporate social policy in Russia: Problems, opportunities, perspectives]. Available at: https://science-education.ru/ru/article/view?id=14707 (accessed 10 September 2018).

5. Analiticheskii obzor po rezul'tatam issledovaniia "Tsennostnye osnovy sotsial'noi deiatel'nosti rossiiskogo predprinimatel'stva" [Analytical review based on the study "Value framework of social activity of Russian entrepreneurship"]. Moscow, 2015, pp. 25-27.

6. Sombart W. Der Bourgeois. München und Leipzig, Duncker \& Humblot, 1913 (Russ. ed.: Zombart V. Burzhua. Moscow, Nauka, 1994, 448 p.).

7. Blaug M. Owen, Robert. In: Great economists before Keynes: An introduction to the lives \& works of one hundred great economists of the past (Russ. ed.: Blaug M. Ouen, Robert. 100 velikikh ekonomistov do Keinsa. St. Petersburg, Ekonomikus, 2008, 352 p.).

8. Schultz T.W. Investing in people: The Economics of population quality. Berkeley, University of California Press, 1981, 173 p.

9. Bekker G.S. Economic analysis and human behavior (Russ. ed.: Bekker G.S. Chelovecheskoe povedenie: ekonomicheskii podkhod. Moscow, HSE, 2003, 672 p.). 
10. Stewart T.A. Intellectual capital. The new wealth of organizations (Russ. ed.: Stiuart T.A. Intellektual'nyi kapital: novyi istochnik bogatstva organizatsii. Moscow, Pokolenie, 2007, 366 p.).

11. McConnell C.R., Brue S.L. Economics. Principles, Problems, and Policies (Russ. ed.: Makkonell K.R., Briu S.L. Ekonomiks. Moscow, INFRA-M, 2003, 983 p.).

12. Zarubina N.N. Etika sluzheniia $\mathrm{i}$ etika otvetstvennosti v kul'ture russkogo predprinimatel'stva [Ethics of service and ethics of responsibility in the culture of Russian enterpreneurship]. Obshchestvennye nauki i sovremennost', 2004, no. 1, pp. 96, available at: https://mgimo.ru/files/33051/33051.pdf (accessed 1 October 2018).

13. Novikova V.F. Investitsii $\mathrm{v}$ chelovecheskii kapital $\mathrm{v}$ Rossii kak faktor sotsial'no-ekonomicheskogo razvitiia strany [Investment into human capital in Russia as a factor of socio-economic development of nation]. Sovremennye tekhnologii upravleniia, 2014, no. 2(38), available at: http://psyjournals.ru/ files/63174/39_Novikova.PDF (accessed 22 November 2017).

14. GOST R ISO 26000-2012. Rukovodstvo po sotsial'noi otvetstvennosti ISO 26000:2010 [ISO 26000:2010. Guidance on social responsibility]. Available at: http://allgosts.ru/03/100/gost_r_iso_26000-2012 (accessed 27 September 2017).

15. Shikhverdiev A.P., Seriakov A.V. Sotsial'naia otvetstvennost' biznesa kak element effektivnogo korporativnogo upravleniia [Corporate social responsibility as an element of effective management]. Vestnik Nauchno-issledovatel'skogo tsentra korporativnogo prava, upravleniia $i$ venchurnogo investirovaniia Syktyvkarskogo gosudarstvennogo universiteta, 2008, no. 1, available at: http://koet.syktsu.ru/vestnik/2008/2008-1/8/8.htm (accessed 7 September 2018).

16. Doklad o sotsial'nykh investitsiiakh v Rossii - 2014: $\mathrm{k}$ sozdaniiu tsennosti dlia biznesa i obshchestva [Report on social investment in Russia - 2014: For Creation of value for business and society]. Available at: http://www.amr.ru/upload/iblock/da4/ da487a01f2bed5773ea4e9f8523567fc.pdf (accessed 4 September 2018).

17. Nifaeva O.V. Aktivizatsiia sotsial'noi otvetstvennosti rossiiskogo predprinimatel'stva [Activating of social responsibility of Russian Enterprenuership]. Menedzhment $v$ Rossii i za rubezhom, 2012, no. 5, pp. 42-44.

18. Argunova V.N. Chelovecheskii potentsial kak tsel' i sredstvo obshchestvennogo razvitiia [Human potential as a goal and means of social development]. Transformatsiia chelovecheskogo potentsiala v kontekste stoletiia. Vol. 1. Nizhny Novgorod, NISOTs, 2017, p. 97.

19. XI forum korporativnykh proektov "People Investor" [XI Forum of Corporate Projects "People investor"]. Available at: http://peopleinvestor.ru/ (accessed 4 September 2018).

20. Doklad o sotsial'nykh investitsiiakh v Rossii v 2018 godu [Report on social investment in Russia in 2018]. Available at: http://www.amr.ru/projects/1111/ (accessed 4 September 2018).

Оригинальность $87 \%$

Получено 08.10.2018 Принято 02.11.2018 Опубликовано 03.04.2019 


\section{A.V. Rusheva}

\section{SOCIAL RESPONSIBILITY OF BUSINESS SOLUTIONS}

The article considers an important aspect of management activity connected with social consequences of decisions made, which have an ambiguous influence on the society. Development and control over the following implementation of managerial decisions is a key function of any manager. The result of managerial work largely depends on the personal qualities of the decision maker, his/her professional competence, the system of value orientations. The paper provides examples of the main motives and initiatives typical of the subjects of business structures, related to socially oriented practices. Despite their presence, the principles of corporate social responsibility are not always taken into account in making managerial decisions, because along with subjective reasons there are various objective limitations.

The examples given in the article are those of implementing social programs and activities by both foreign and domestic enterprises testify to some extent to the motivation and goals of achieving social welfare. But the analysis of practical achievements in the field of corporate social responsibility in Russia reveals their rather modest scale, in comparison with foreign companies. The list of some of the most obvious consequences of the activities of socially irresponsible domestic organizations and the description of scientific concepts and works created on the basis of a deep reconsideration of the purposes of entrepreneurial activity put the problem under consideration into focus, make us think about the need to apply the rich experience of social charity, investment in human capital, ensuring the sustainable functioning of the enterprise in the market and obtaining other positive social and economic benefits.

The main conclusions of the analysis of the problem are the recommendations on the application of a systematic approach to the development and adoption of management decisions, which provides a more comprehensive view of the situation, allowing to take into account not only the economic and political interests of management, but also the many social consequences of actions taken. Also, according to the author, it is important to codify the principles of corporate social responsibility in the relevant organizational documents, to think over the mechanism of their implementation.

Keywords: social responsibility, management decision, manager, organizational environment, corporate governance, state, achievement of goals, motivation, social welfare.

Anna V. Rusheva - Candidate of Sociological Sciences, Associate Professor, Department of Sociology and Social Work, Lobachevsky State University of Nizhny Novgorod, e-mail: avr0201@yandex.ru.

Received 08.10.2018 Accepted 02.11.2018 Published 03.04.2019 